\title{
Supply Risk Management: an empirical perspective on the Italian manufacturing sector
}

\author{
Marco Perona
}

\begin{abstract}
Frame of the research: This paper presents the preliminary results of a large-scale research conducted through a survey on 147 Italian manufacturing companies, which focuses on supply risk.

Purpose of the paper: Our analysis investigates two main research questions: first, to measure out how likely it is that a supply chain gets disrupted by the sudden and unforeseen interruption of supplies; second, which are the main cause(s)that can lead to such an occurrence
\end{abstract}

Methodology: We analyzed 157 such cases reported by the 147 firms in our sample.

Findings: Our preliminary results highlight that the occurrence of supply disruptions is rather frequent, and that suppliers' financial default is by and large the most frequent single cause, being at the root of almost half of such cases. By breaking down these results by firm size and industrial sector, we uncover that both these exogenous factors have a deep influence on each of the studied effects, the occurrence frequency, and the causation.

Research limits: This study -as any other empirical research-has limitations in both the number and type of firms scrutinized and is constrained to a specific time period; however, it provides clear outcomes and robust statistical analysis.

Practical implications: Moreover, in doing so it presents managers with some critical considerations about their current curse of action regarding supply chain risk management, and how it could become more efficient and effective.

Originality of the paper: This paper fills a gap in the extant literature by supplying robust quantitative data regarding the frequency of supply interruptions and their causation

Key words: supply chain; risk management; supply risk management; supply interruptions; supplier default

\section{Introduction}

A Supply Chain (SC) is often defined as an eco-system of enterprises that interact in a networked and interconnected process, in order to fulfill the needs of a certain final customer (Cooper and Ellram, 1993). A supply chain is typically characterized by 3 main flows: the physical flow of materials and goods, that normally goes from up to downstream; the information flow that moves either direction, and the financial flow, that typically moves from downstream up. Consequently, Supply Chain 
Sinergie

Vol. 39, Issue 3, 2021

Management (SCM) can be seen as the coordination of these 3 flows, and the actors that are connected by them. Broadly speaking, the main goal of SCM is to ensure that the correct material or product with the correct information is positioned in the right moment and in the right place when a customer will require it. Cigolini et al. (2004) describe a set of different types of supply chain and consequently different goals and coordination strategies.

Amongst the various functions and aims pursued by SCM, supply chain continuity is defined as the capability of a Supply Chain to remain in business despite disruptions that might affect any of the chain's actors or any of the three main flows. Following Blos et al. (2015) to ensure supply chain continuity is important not only because it keeps the business running, thus safeguarding the interests of its key stakeholders. It is also of paramount importance to protect the firm's reputation, by keeping its brand and value creating activities alive.

The standpoint approach here considered is the general model of entrepreneurial risks supplied by the ISO 2002 norms. Following ISO (Krolas and Krolas, 2010) any industrial risk can be modelled by: the probability of the unwelcome event to take place, and the amount of the losses it could generate in the focal organization if it was to occur. This model is applied to the context of supply risk from the customer's perspective, by considering the probability of a supply relation's interruption, and the damage it could generate in the customer's business.

This paper presents some highlights from a survey conducted in the Italian manufacturing sector in 2019. To this purpose, the paper is structured as follows: in the following section an aggregate perspective is presented on the theoretical background of supply risk management and its main developments; further, the methodology applied in this study is presented by describing how the survey through which data was collected was designed and executed and by describing the main features of the data sample collected. The description of some of the main empirical findings is then reported. The following section discusses the findings presented, both in a theoretical perspective and in the light of their managerial implications. Finally, a concluding remarks section closes the paper.

\section{Theoretical Background}

\subsection{Business risk and risk management}

The concept of risk in business has undergone a sharp development, starting from its first description in the seminal book of the Princeton's mathematician John von Neumann and economist Oskar Morgenstern "Game theory and economic behavior" (1944). In that book they firstly introduced two concepts: the concept of "risk", connected to a harmful event whose probability distribution is known, and the concept of "uncertainty" when we know that a certain detrimental event could happen, but its probability distribution is unknown to us. Their famous "expected utility theory" was the first attempt to model a rational decision-making approach 
referred to such situations. Its main limitation, the consideration of a fully rational behavior, was addressed by the psychologists Daniel Kahneman and Amos Tversky (1979). By introducing their "Prospect Theory" on decision making under risk for the first time they took into consideration the idea that decisions can be far from fully rational, for several reasons, such as the usage of empirical and approximated rules or the so called "herd effect". One further credit we owe to these authors is their idea that risk should not only be considered a negative concept, mainly because it is the main source of opportunity.

The modern and generally accepted definition of corporate risk, that is encoded within the "Risk Management - Principle and Guidelines» International Standard ISO 31000:2009 (2009) is to model risk as the combination of two aspects: the likelihood of the harmful event occurrence $\mathrm{P}$ (event) and the amount of the losses $\mathrm{L}$ (organization, event) that the focal organization would undergo if that same event should occur. Therefore, the risk $\mathrm{R}$ that an organization undergoes in connection with a specified event can be expressed as:

$\mathrm{R}$ (organization, event $)=\mathrm{P}($ event $) \mathrm{x} \mathrm{L}$ (organization, event $)$

With regard to this definition, a wide number of frameworks have been proposed in literature about the classification of corporate risks. For instance, Prandi (2010) proposes two risk classification profiles: the first criterion is about the risks' origin, encompassing "internal" as well as "external" risks. Internal risks derive from events and decisions that are endogenous to the focal organization, such as manufacturing plants failures, while external risks depend on exogenous facts and decisions (e.g. competition or geo-political instability). The second criterion distinguishes among "pure" and "speculative" risks. Pure risks depend on sudden events with a sudden effect, that cannot be foreseen or modified before their occurrence, but can typically be transferred to other subjects, for instance with the practice of insurance: a car accident is the typical example of a pure risk. On the contrary, speculative risks are connected to future and unknown evolution of current and known phenomena such as the economic trend, or the competitive realm, and can thus be addressed by actions performed ex ante.

And indeed, matching the development of both the definition of what is risk and the classification of various types of corporate risks, also the managerial discipline of risk management (Avenn, 1992) has sharply evolved in time. It basically consists in all the courses of action protecting the focal company's assets and revenues in time. Two main schools have built on this basic concept: a financial risk management school that deals with corporate risk by mainly transferring it by means of an insurance policy; and a business risk management school, that has mainly resorted to the contingency planning and business continuity management, aimed at modifying the business practices and managerial choices in a way to reduce both the likeliness of occurrence of unwanted events and their perspective effects (Ahmed et al. 2007). By blending these two approaches, corporations have evolved (or are in the process of evolving) their risk management
Marco Perona

Supply Risk Management: an empirical perspective on sector 
sinergie Vol. 39, Issue 3, 202

practices, starting from an unstructured and "silos-oriented" manner in which each manager is entitled to take care of risks occurring within their domain, and moving towards a more integrated and centralized approach in which an appointed and professionally prepared "risk manager" is entitled to identify and measure all risks relevant at a corporate level, and to co-ordinate the plans and policies most appropriate to handle them. This new approach is often referred to as Enterprise Risk Management (ERM), as defined by the International Standard ISO 31000:2009 (2009).

\subsection{Supply chain risk management}

The idea that theory and practice about risk and risk management could be applied to supply networks started to be considered in the first years of this century. Research in this domain developed at a fast pace in the last 20 years or so, and as claimed by Sodhi et al. (2012) it came from many diverse, and complementary fields. The main reason for this fast development, was highlighted by Utta Jüttner (2005) who pinpointed the companies' generalized expectation that the vulnerability of their supply chains could increase in the next five years. On the other side, she argued that the concept of supply chain risk management was still in its infancy for the time being. A first exploratory study of this topic was proposed by Zsidisin et al. (2000) and Zsidisin (2003), who interviewed purchasing professionals in several firms. They discovered that purchasing organizations often create contingency plans and implement processimprovement and buffering strategies in response to perceived supply risks discovered in assessments. But, even though risk assessments, contingency plans, and risk management efforts are generally acknowledged as being important, many of those interviewed believed that there was not enough done in their organizations to mitigate supply-related risks. Thus, by putting Jüttner's and Zsidisin's results together, we can observe that on the one side firms expect environmental uncertainty and supply chain's vulnerability to increase in time, while on the other they believe they are not doing enough to prevent and mitigate disruptions.

Once the corporate relevance of supply chain risk became clear, one first stream of research was about how to analyze and measure-up the risk faced by companies. Hallikas et al. (2002 and 2004) highlighted how a company can analyze and assess the risks associated with networking, and the main challenges that network co-operation brings to risk management. They outlined the general structure of the risk management process and presented methods for risk management in a complex networked environment. Most importantly, their results indicate that risk management is an important development target in supplier networks, because when the dependency between companies increases, they become more exposed to the risks of other companies. These results can be considered as a suitable explanation of the above-mentioned increase in supply chain risk perceived by firms. Harland et al. (2003) also provided a practical tool for assessing risk in networked supply chains; they also highlighted that the growing complexity of supply networks is one major driver of the increase in firms' vulnerability to disruptions. More specifically, they investigated the impact 
of such aspects as: product / service complexity, outsourcing, globalization and e,commerce. From this stream of research, thus, we can derive the notion that supply chain risk in both its components of probability and loss is connected to the supply chain complexity, and this in turn explains well why the generalized perception is that the risk is increasing.

Next, researchers started to investigate the specific managerial policies most suited to address supply chain risk, which policies are more effective than others and which are the cause-effect relations that can explain this. For instance, Ojala and Hallikas (2006) tried to improve the understanding of relations between investment decision-making and risks in supplier networks. Their study concentrates on how network companies make investment decisions, what are the main risks related to investing in a network context, and what possible ways are there to manage these risks. By the same token, Micheli and his co-authors (Micheli, 2008 and Micheli et al., 2008 and 2009) worked in deep on how supplier selection can improve supply risk. They developed a risk efficiency-based supplier selection approach for critical supplies, that allows a decision maker to consider the procurement-related "risk" and "investment" with a "total cost" profile related to every supplier and computed as a function of the possible investments that can be made to exploit the upside and to mitigate the downside supply risks. Hult et al. too (2010) investigated supply chain investment decisions when facing high levels of risk uncertainty, on the grounds that given the potential dollar value involved in these decisions, an understanding of how these supply chain decisions are made is of significant theoretical and practical importance. By using the theoretical lens of Real Options Theory these authors provide evidence that options operate differently in supply chains than they do in firms. This result was further invigorated by the research of Wagner and Böde (2006). They were among the first to investigate supply chain risk management practices by means of a large-scale survey: building on the grounds of several hundreds of responses from executives of firms operating in Germany, they found that such supply chain management decisions as a firm's dependence on certain customers and suppliers, the degree of single sourcing, or reliance on global supply sources are relevant for a firm's exposure to supply chain risk. Following their path, Thun and König (2011) surveyed 67 manufacturing plants in the German automotive industry. Their analyses reveal that companies with a high degree of implementation of supply chain risk assessment tools show a better supply chain performance than their less developed counterparts. A 2010 study from Wang et al. also supported these empirical findings. These authors proposed a model in which a firm can source from multiple suppliers to improve supplier reliability. So, from this stream of research we achieve the notion that the choice of suppliers and the main sourcing policies (such as single vs. multiple sourcing, or local vs. global sourcing) can actually affect the amount of risk incurred, and therefore that these policies play a major role in generating or moderating supply chain risk, both by reducing the occurrence probability and the effects magnitude.

Another research stream went further to identify, define and describe several relevant features of supply chain risk management. In 2012 
sinergie Vol. 39, Issue 3, 202

Wieland and Wallenburg firstly defined two firm characteristics relevant to supply chain risk management: robustness, aka the ability to cope with perturbations proactively, and agility, or the ability to cope with them reactively. They empirically found that both agility and robustness are important in improving SC performance. While agility has a strong positive effect only on the supply chain's customer value, but not directly on business performance, robustness has a strong positive effect on both performance dimensions. Pursuing the same research path, in 2013 Pettit et al. were among the first to speculate on the concept of supply chain resilience, building on the experience gained through an unprecedented sequence of globally harmful events. They propose a Supply Chain Resilience Assessment and Management tool. Through mixed-method triangulation, their research identified hundreds of levers that can be used to guide a resilience improvement process and suggested a correlation between increased resilience and improved supply chain performance. Later on, Heckmann et al. (2015) went further by providing an overview of quantitative supply chain risk management approaches, and a comprehensive definition of the main related concepts. In $2021 \mathrm{El}$ Baz and Ruel investigated a sample of 470 French firms in the face of the COVID-19 induced disruption. They found that the implementation of adequate supply chain risk management practices can and does mitigate the effects of the COVID-19 outbreak. They considered four main steps of supply chain risk management, formerly: risk identification, risk assessment, risk mitigation and risk control, and by means of their research structure they tested the effect of these 4 classes of actions on both supply chain resilience and robustness. Their findings reveal that all four supply-chain risk management practices affect positively resilience, while only risk identification and control influences robustness. These works on the one side greatly improved our understanding of the supply chain risk phenomenon, and on the other side provided a long list of mitigating levers, together with rational ways to classify them.

Further developments investigated the respective effectiveness of internal vs. external levers. A study from Wiengarten et al (2016) further built on the concept of supplier relations, and, by means of an international survey, found that supplier integration is an effective lever to improve supply chain performance and decrease supply chain risk also in countries whith a weak rule of law (i.e., intrinsically high-risk environments). This conclusion was further reinforced by Hallikas and Lintukangas (2016), by means of an empirical study on a set of Finnish companies of various sectors. They found that a greater supplier orientation, as well as an improved supplier integration both support an improvement of supply chain risk management performance. Supplier orientation can be characterized as collaboration with suppliers in such areas as: risk measurement, goal setting, business process development, error handling, etc. In 2016 Mishra et al. performed an empirical study on 184 Indian firms in order to examine the effect of supply risk management of 2 such focal policies as buffering (aka, decoupling one firm from its supply chain by means of a considerable amount of inventory dislocated both upstream and downstream, and bridging, that is the establishment of strong linkages with trading partners 
both up and downstream. They found that both policies are positively connected to a reduction of the supply chain disruption risk experienced by firms, and that in turn this sharply improves the downstream supply chain performance. In 2017 Revilla \& Saenz presented one comprehensive survey reporting the correlation of supply chain disruptions with how supply chain risk was managed within each firm. By subdividing scrutinized companies in four supply chain risk management classes, namely: passive, internal, collaborative and integral, they found that firms pursuing an inter-organizational orientation (collaborative and integral) face the lowest levels of supply chain disruption. On the contrary, strategies which simply concentrate on having greater control of internal operations are not vigorous enough to stop the cascade effect of a disruption at the supply chain level. This evidence strongly suggests that it is the inter-company collaboration between suppliers and customers in proactively designing and putting in place countermeasures in advance that decisively improves one supply chain's resilience rather than just putting one company's operations under control.

\subsection{Open questions}

The literature review just exposed in chapter 2.2. critically illustrates the main developments of the supply chain risk management research in the last 20 years or so. It firstly recognizes the relevance of reducing both the frequency and the impact of supply chain disruptions in improving downstream supply chain performance, as well as the increasing impact of supply perturbations as a result of the multi-dimensional increase in supply chains' complexity. It further developed this discipline's theoretical foundation, by defining such constructs as robustness, agility and resilience and by identifying several levers and policies that can in principle contribute to mitigate the risk by either reducing the likeliness of disruptions or the magnitude of their effects. It further recognized the peculiar value of external levers as compared to internal ones in moderating the risk and provided a rational description of the risk management process by organizing it in 4 well-defined phases. All these advancements have greatly contributed to developing and deepening the theoretical knowledge of this phenomenon, while leaving some space open especially in practice.

In 2011 Tang et al. investigated the research developments of supply chain risk management by presenting a comprehensive literature review on this topic, due also to the rise in global attention tributed by the research community in the first decade of the century. Through their review, they identified some relevant gaps between theory and practice: for instance, though they found a pressing need and awareness of supply chain risk management from firms, they report that quantitative models in the field are relatively lacking. Another of their findings is that a statistically significant increase in the research on this topic took place during years 2000-2005 together with an evolution from passively reacting to vague general issues of disruptions towards more proactively managing supply chain risk from a more global perspective. In agreement with Tang et al. (2011) the study of Revilla and Saenz (2017) also uncovers that to date studies on supply
Marco Perona

Supply Risk Management:

an empirical perspective on

the Italian manufacturing sector 
sinergie Vol. 39, Issue 3, 202

chain risk management have been more theoretical and qualitative than empirical and quantitative, so we are failing to know the precise extension of this phenomenon in practice. In facts, Bode and Wagner (2015) as well note that one important element of risk that remains largely unexplored is the frequency (or likelihood) of supply chain disruption. Most studies have investigated the firm's losses if a disruption actually occurs (Hendricks et al., 2009) but have failed to illustrate such relevant aspects as how often this happens and why it occurs.

This gap is precisely this paper's standpoint. We have performed a thorough empirical study in almost 150 Italian manufacturing firms with the aim to take a quantitative picture of the supply chain disruptions they experienced, and to answer to such questions as: how frequently do major supply chain disruptions happen? What are the causes behind these major disruptions? None of these questions finds an answer in any of the studies that were issued in the specialized literature to date, up to our best knowledge.

\section{Methodology}

\subsection{Data collection}

The information used by this study belongs to an extensive online survey that was answered by 147 Italian manufacturing firms, in line with Hoffmann et al. (2013). The online questionnaire was prepared with the Survey Monkey platform. It consisted of around 150 questions, that took at least 2-3 hours to a generic company to answer. Topics within the questionnaire were arranged as follows:

a) General data regarding the responding company

b) How the responding company addressed the definition, measurement and management of supply risk

c) Thorough description of (up to) 3 cases of supply interruption suffered in the last 10 years

d) Time and cost implied by the search and selection of a new supplier

e) The main features of the responding firm's supply network

f) The main tasks and responsibilities undertaken by the responding firm's Purchasing Department

g) General data about the respondent person

The questionnaire was administered to around 2.000 randomly chosen Italian manufacturing firms. Within each firm we chose to address the manager most suited to answer the questionnaire, typically a $\mathrm{CPO}$ (Chief Purchasing Officer), a SCM (Supply Chain Manager) or a CEO (Chief Executive Manager), especially for smaller firms.

The questionnaire administration took around 5 months at the end of 2019. The full mailing list was divided in 20 lots, each encompassing around 100 firms. Each week one lot of emails was sent, and the following week all 100 firms were contacted on the phone to expedite the questionnaire filling. Owing to the rather long time required to fill the questionnaire, due to the high number of questions, many of which require quantitative data, 
it was necessary to recur to a lot of phone expediting, in order to obtain 163 answers overall, with a hit ratio of around $8 \%$.

Following the data collection phase, empirical data collected were verified: any time one or more answers were missing or potentially outliers, the information was double checked with the manager that gathered it, and when it was not possible to fix the problem, the corresponding questionnaire was eliminated. At the end of this process, we obtained 147 complete and dependable questionnaires, that were used for the following phase of elaboration.

\subsection{Sample description}

In order to describe the sample of responding firms, we analyzed various endogenous as well as exogenous aspects. Figure 1 presents the sample breakdown by firm dimensional size and industry. We considered as "micro" firms with sales of 10 million $€$ or less; "small" those in the range 10-50 m€; "middle" in the range 50-200 m€; and "large" if their sales are in excess of $200 \mathrm{~m} €$. Our sample represents well all four classes but fails to match the intrinsic distribution of Italian firms by size, that tends to be much more on the micro and small dimensions. Quite evidently, the very topic addressed by the survey determined a bias, as small and micro companies tend to care less about supply risk than their larger counterparts and as a result had a lesser response rate.

Fig. 1: Firm sample breakdown by dimensional size (left) and by industry (right)
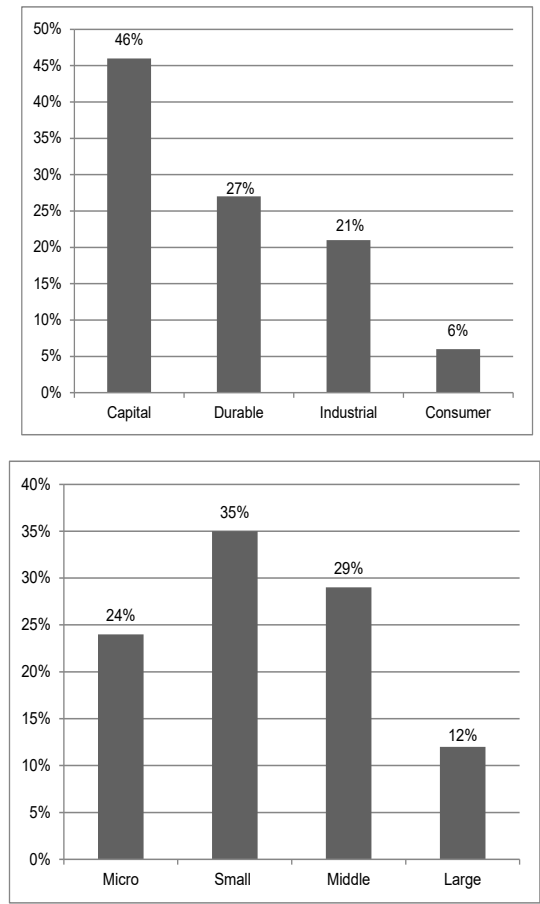

Source: Elaboration from survey's database
Marco Perona Supply Risk Management: an empirical perspective on the Italian manufacturing sector 
sinergie

Vol. 39, Issue 3, 202

A second dimension we used to describe our firms' sample is the branch of industry each company belongs to. In order to simplify this analysis, we used the simplified classification proposed in figure 2 .

Fig. 2: Classification of firms by industrial sector

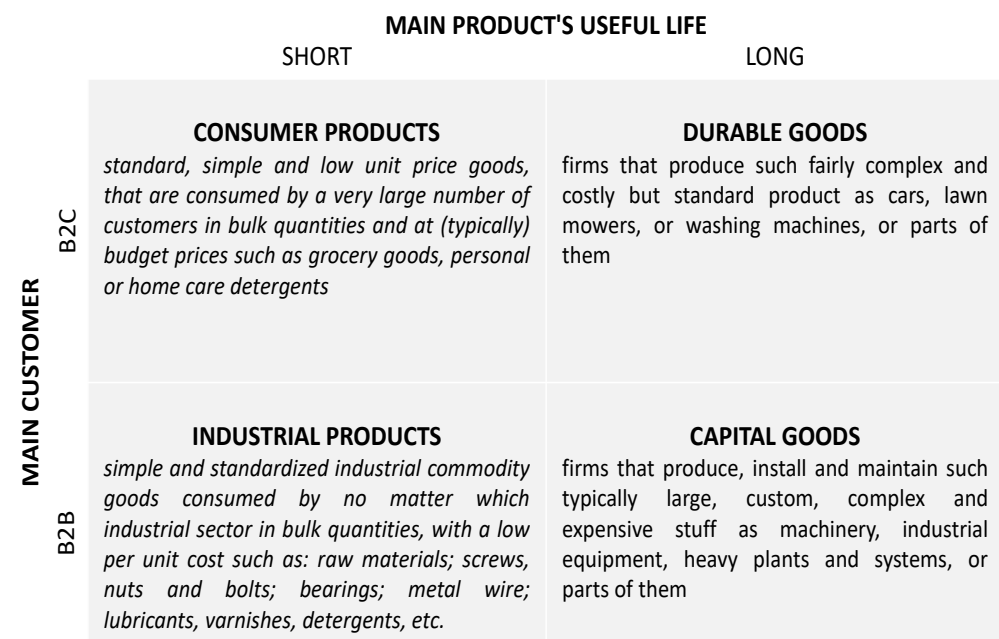

Source: Elaboration from survey's database

Overall, almost half of the responding companies belong to the capital goods sector, mainly within the micro, small (where they constitute almost $2 / 3$ of the sample companies) and medium dimensional sizes. More than $1 / 4$ of the scrutinized companies belong to the durable goods sector, especially in the medium and large dimensional sizes (where they account for almost half the scrutinized firms). And around $1 / 5$ of them belong to the industrial goods sector, while just a limited fraction of scrutinized companies operates within a consumer products sector.

Figure 3 illustrates the average number of active suppliers of direct materials found respectively by firm size and by industry. Fully in line with expectations, we found that the number of suppliers is strongly connected with the firm's size, with an absolutely wide difference among micro (that on average have little more than 100 suppliers) and large firms (with almost 1.000 suppliers on average). Industry, and especially the structural complexity of goods traded in each industry, is found to be another relevant factor at the base of the number of suppliers. Consumer packaged goods firms are at bottom with little more than 160 suppliers on average, despite the fact that they tend to be rather large firms, and capital goods are on top with more than 400 suppliers on average, despite being on average micro or small firms. As a whole, and matching expectations, firms within B2C industries tend to have less suppliers than their $\mathrm{B} 2 \mathrm{~B}$ counterparts, and short-life products manufacturers tend to have less suppliers than their long-life counterparts. 
Fig. 3: Average n. of active suppliers of direct materials by firm size (left) and by industry (right)
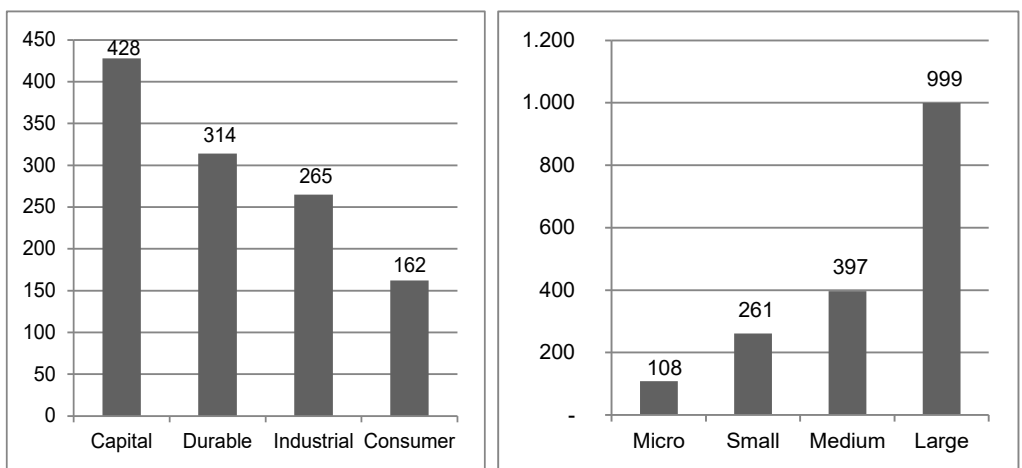

Marco Perona

Supply Risk Management: an empirical perspective on the Italian manufacturing sector

Source: Elaboration from survey's database

\subsection{Research questions}

As it was highlighted in chapter 2.3, much of the extant literature on this subject adopts a theoretical rather than practical and a qualitative rather than quantitative standpoint. As a matter of fact, there is a lack of studies devoted to measuring out such quantitative aspects as the likelihood and frequency of major supply chain disruptions, or the motivations that determine them. It seems quite awkward that these pieces of information are still missing, especially in the light of the structured and elegant theoretical foundations that were set for the supply chain risk management discipline, since this knowledge is key in order to address and channel both preventive and reactive actions. In fact, El Baz and Ruel (2021) suggested to develop supply chain risk management courses of actions in 4 logically distinct stages: risk identification, risk assessment, risk mitigation and risk control. In other words, they supported that, in order to mitigate risk with appropriate preventive actions and/or control it with suitable reactive actions, you firstly have to know which risk you are coping with (identification) and then you should measure it (assessment). Even more strange, in the light of Jüttner's (2005) claim that on average managers expected their supply chain's vulnerability to increase in years to come. Thus, this study builds on the empirical data collected about major supply chain disruptions in order to shade some light on these very issues. By "major supply chain disruptions" we considered the interruptions of the supply chain continuity that are generated any time one supplier, for one reason or another, stops supplying a customer with one or more (material or immaterial) items in an unforeseen and sudden way, which might leave the customer unprepared to cope with.

Hence, the first research question addressed by this study is about the frequency of occurrence of such events:

RQ1: what is the frequency with which supply chain interruptions occur?

By answering to this question, we firstly fill the corresponding gap in the extant literature, and secondly, we will provide managers with 
sinergie Vol. 39, Issue 3, 2021

a fundamental piece of information to identify if this is a marginal phenomenon that does not deserve much of their attention, or if -on the contrary- it is a fundamental issue to keep in control by investing in identification, assessment, mitigation and control activities.

By the same token, the second research question investigated by this paper is about the causes of major disruptions experienced by the investigated firms:

RQ2: is there one "main" cause that generates major supply chain disruptions, or does a full set of different causes play a similar role in this phenomenon?

By answering to this second question not only we will fill the corresponding gap in the extant literature, but we will also provide managers with another valuable piece of information, that will help them to better direct their supply chain risk management efforts.

Secondary to both research questions, we will investigate if and how some exogenous or endogenous factors have an impact in this causation process.

\section{Empirical findings}

In order to address the two research questions considered by this paper, we asked each of the 147 responding firms in our survey how many major supply-chain disruptions they had experienced in the previous 10 years (i.e. 2010-2019) and -if any- to describe in detail up to three of them that they considered particularly relevant. Our sample of 147 responding firms yielded as much as 261 overall cases, reported by 73 firms (slightly more than 3,5 per firm), while 74 firms did not report any such case. Cases described in detail were 157, with an average of slightly more than 2 per each of the 73 firms that presented them. For the sake of clarity, we collected our data in Italy (slightly) before the COVID-19 outbreak, so this is not considered within the reported causes. All the sample differences illustrated in this chapter have been tested statistically significant at least with a $95 \%$ probability.

\subsection{Research question 1: evaluating the frequency}

As we anticipated, the 147 respondents reported in total 261 supply interruptions in the 2010-2019 decade, with the frequency distribution indicated in figure 4 . Note that since data were collected in the middle months of 2019, data regarding this year is not complete. This means an average of 1,77 supply interruptions per company every 10 years, which in turn means that the average firm in our sample has a $17,7 \%$ probability of incurring in one unforeseen supply interruption per year. In our sample 74 companies declared to never have incurred a supply chain interruption in the previous 10 years: so, if we exclude these "lucky" firms, the average number of interruptions per company and per 10 years is around 3,6 which takes the average disruption probability per annum at around 36\%. These 
are by no means trivial frequencies: quite the contrary, considering the financial impact that each supply interruption can have on the company that experiences it, these data definitely suggest taking this problem to the sector Marco Perona Supply Risk Management: an empirical perspective on attention of the firms' senior management.

Fig. 4: Number of supply interruptions experienced by responding firms

in years 2010-2019

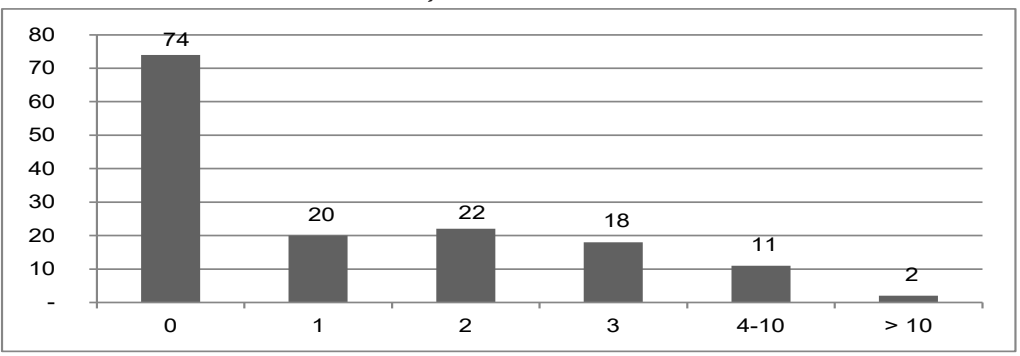

Source: Elaboration from survey's database

Since in section 3.2. it was illustrated that firms in the sample tend to have very different number of suppliers on the base of their dimensional size and industry, we decided to compute a new variable that makes the rate of supply chain interruptions comparable among firms regardless their number of active suppliers. To do so, we computed for each firm the average $\mathrm{n}^{\circ}$ of supply interruptions experienced per year and per each 100 suppliers. The breakdown of this new variable by firm size and by industry is reported in figure 5 .

Fig. 5: Average n. of supply interruptions per year and per 100 suppliers by firm size (left) and by industry (right)
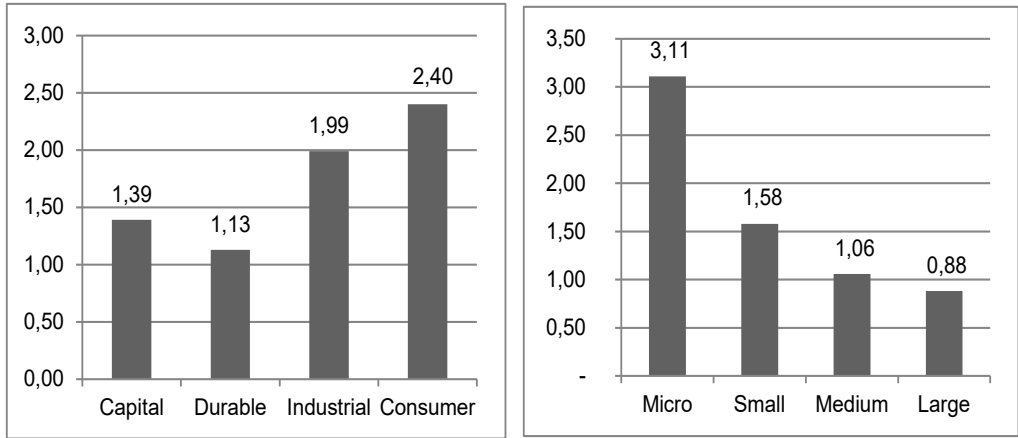

Source: Elaboration from survey's database

The empirical evidence collected here shows that, even though larger firms tend to experience more supply interruptions than smaller ones, when we report this figure to the overall number of active suppliers the result is turned around, because larger firms tend to experience more or less one quarter of the supply interruptions suffered by smaller ones relative to their number of active suppliers. This evidence sets a strong suggestion that 
sinergie Vol. 39, Issue 3, 202

larger firms might count on more complete, straightforward and effective supply chain risk management systems, encompassing more complete organizational procedures, more skilled or experienced managers, and ad hoc software tools, all features that typically micro or small companies lack of.

Much the same observation can be made regarding the breakdown by industry. Firms in Capital and Durable goods supply chains have on average more supply interruptions per year than their counterparts in other industries: but if we consider that they tend to have on average more active suppliers than their industrial and consumer goods counterparts, we end up with the evidence that firms in these two industries tend to experience on average less interruptions per year and per 100 suppliers than their counterparts in short-useful-lived products industries, in the face of the higher complexity they have to manage, in terms of product range, product structure, supply base dimension and stability, level of product's customization, etc. This result is partly at odds with previous more theoretical literature, for instance Hallikas et al. (2002 and 2004) and Harland et al. (2003), that supported a positive relation between supply chain complexity and firms' vulnerability to supply interruptions.

So, we can answer to our first research question that the average probability to experience at least one supply interruption in a given year for firms in our sample, at almost $18 \%$, was found to be higher than expected. Moreover, it was found to be strongly correlated to both the firm dimension and its industrial sector, but in a rather counterintuitive way.

\subsection{Research question 2: finding the cause(s)}

In order to investigate the causation process that is at the base of the major supply-chain disruption reported, we resorted to the 157 cases described in detail. In order to leave as much freedom as possible in the choice of the cause, we let respondents free to indicate whether they knew or not the precise cause at the root of the supply flow interruption they had experienced, and in case to describe it in words. $100 \%$ of reported issues were known and described, and we post-processed them to obtain as few standardized groups as possible. Results are exposed in figure 6.

Fig. 6: Major supply chain disruption breakdown by cause

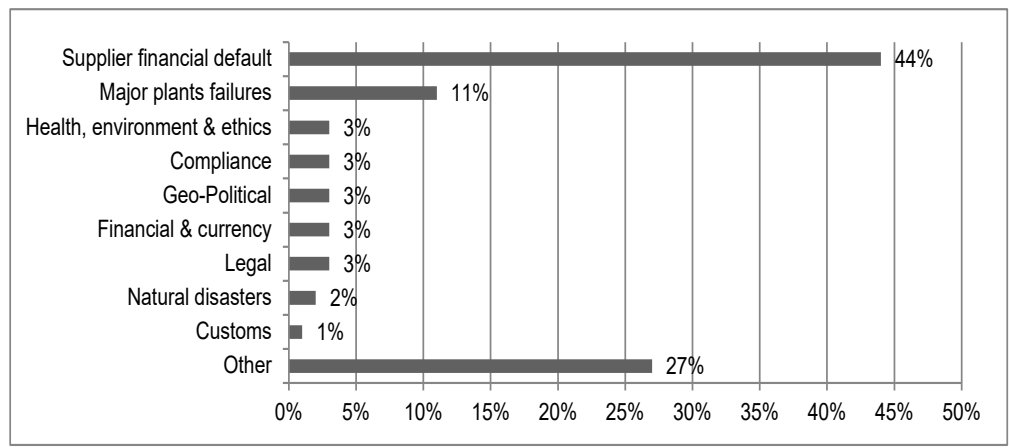

Source: Elaboration from survey's database 
Unfortunately, we were unable to obtain as few standard groups as we had liked to, on the account of the extreme sample's dispersion. We classified as "other" all the (42!) different reported causes that had happened just 1 time in our data sample and that we could not connect or join to another larger group: this is an extremely wide set of very differentiated causes, from the supplier going out of business following the founder's retirement, to the personal quarrel between the representatives of the two trading partners, and from a cyberattack on the supplier's servers to the supplier's choice to divest from a specific sector, and much, much more. These are all events that can happen, and actually did, but are very, very unlikely, the typical once-in-a-lifetime events that probably could never happen again in the next few years. Next come custom issues, one cause that occurred only 2 times over 10 years in our sample of 147 firms. Natural disasters are reported having caused just 3 supply interruptions out of 157 . Legal, currency, geo-political, compliance and health or environmental issues were reported each to have caused between 4 and 5 cases. In short, all of these causes despite recurring sometimes in our sample are clearly very infrequent and unlikely. Slightly more important as a cause of supply chain discontinuity was the recurrence of production plants failures, which happened 17 times in 10 years and over 147 firms: however, while this should be regarded as a non-negligible number of times, it still remains a fairly unimportant occurrence if we compare it with the number of years and our sample dimension.

Without any doubt, on the other hand, suppliers' financial default emerged as the widely most relevant cause of reported interruptions, accounting on its own for almost $50 \%$ of cases described in detail. If we apply this percentage to all the 261 reported (but not described in detail) cases we obtain 115 cases over 10 years and 147 firms, which yields an average probability of almost $8 \%$ per firm and per year. This is definitely a relevant probability: if we do the same computation for the second most relevant cause, the plants failure, we obtain, by contrast, 29 cases overall, or slightly less than $2 \%$ average probability per firm and per year, which appears definitely less interesting from a managerial perspective. If we add that while a plant failure can in principle be fixed while financial default can typically put the entire supplier company out of business forever, it is fair to answer our first research question in an affirmative way: on the ground of our empirical evidences, we find that suppliers' financial default is by and large the most relevant of all the numerous possible causes that can explain why all of a sudden and without much warning a certain supply is interrupted.

It is now interesting to examine whether any of the exogenous factors utilized in section 4.1. has a relevant impact on the causation process as well. To do so, we grouped causes in 2 only classes: supplier financial default and all the other causes. Figure 7 reports the causes breakdown by firm dimension and industrial sector. As it appears very clearly by the two charts, both factors play a major role in shaping also the causation process. More in detail, with regard to firms' dimension, the larger the firm, the larger the portion of supply chain disruptions that is directly and uniquely caused by suppliers' financial default, and the smaller the portion 
Sinergie

Vol. 39, Issue 3, 202

that can be attributed to the numberless other causes. Since it is fair to think that larger companies can on average count on more sophisticated, complete and effective supplier selection and evaluation procedures than smaller ones, which was already proposed as a suitable explanation for the overall smaller rate of disruptions suffered by larger companies, one possible explanation of this empirical evidence is that large $(\mathrm{r})$ companies might be (much) better than smaller ones at filtering the many small and infrequent causes that seem to haunt micro and small firms' supply chains, while firms' ability at predicting their active suppliers' defaults seems almost untouched by firms dimension. In turn, this could be an indication that these larger companies tend to invest more in supplier selection (so to avoid, for instance, customs or currency issues) and in setting supply contracts (so to prevent, say, legal or compliance issues) than they do in checking their suppliers financial accounts.

Fig. 7: Causes breakdown by firm dimensional size (left) and by industry (right)
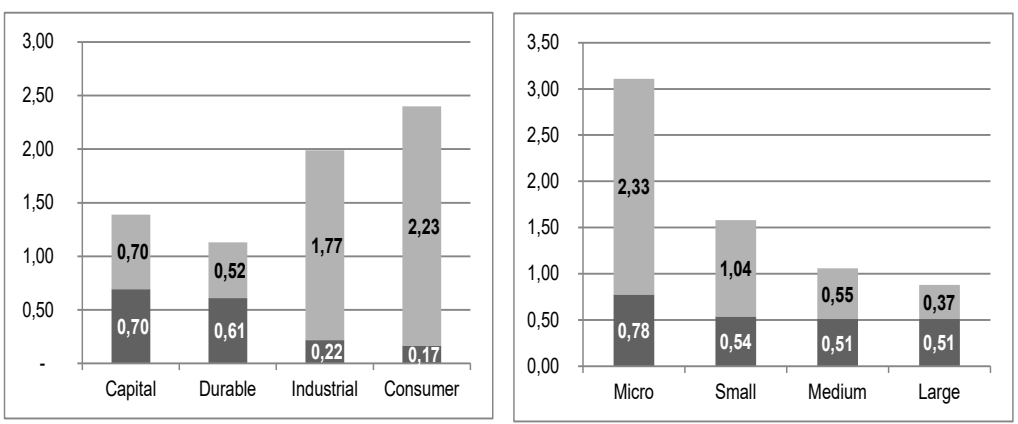

Source: Elaboration from survey's database

The industry to which each responding company belongs plays a major role in the causation process too, as far as we can see from our empirical evidence presented in figure 7. Again, to break down results illustrated in figure 5 by cause, turns our results around. Firms in the two industries that deal with most complex products (namely, capital and durable goods) show a much higher incidence of the supplier's financial defaults than their counterparts in sectors that manufacture simpler and shorter-lived products (industrial and consumer goods). This could be explained by considering that these sectors have by far the most complex supply chains, in terms of number of suppliers (see figure 2), products range variety and structural complexity, number of customers, etc. If this explanation holds true, we could have achieved an empirical demonstration of the supply chain vulnerability vs. complexity connection recalled by Hallikas et al. (2002 and 2004) and Harland (2003), an explanation that holds especially true for suppliers' financial default, rather than for any other possible cause of supply interruption.

Our empirical findings support a definitely affirmative answer to our second research question, because financial default was found to be by and large the main cause of supply interruptions, with almost half of the cases, 
while the second most frequent cause, namely production plants failures, can explain slightly more than $10 \%$ of cases. We uncovered many tens of other causes, all of them happening just episodically over the analyzed firms and time period. The causation process has been investigated also by combining this variable with 2 exogenous factors: all of them proved to have a statistically significant impact on the causation process. We found that larger firms are much better than their smaller counterparts at filtering almost any cause of supply chain interruption, apart from supplier financial default, the largely main one: this evidence is so strong that it holds true even if larger suppliers (that are understandably chosen more frequently by larger firms) tend to have a much reduced rate of default as compared to micro ones (that are particularly abundant on the smaller companies supplier base). A greater percentage of defaults is also found in association with firms that operate in sectors that produce more complex goods with a longer useful life, such as capital or durable goods, as compared to their short useful life counterparts, on the account that both capital and durable goods tend require more complex product range, product structure, supplier bases, etc. confirming the link between supply chain complexity and its vulnerability to perturbations.

\section{Discussion}

The empirical findings illustrated in this paper are preliminary results achieved through a wide scope research program in the Italian manufacturing sector. While the analysis of the data collected will proceed further and it will hopefully yield new and more relevant evidence, we deem that the evidence presented in this paper is noteworthy both from a theoretical perspective and from a practical point of view.

\subsection{Theoretical discussion}

One criticism that has been risen by some authors is that, up to date, research on supply chain risk management has been too much oriented towards theoretical vs. practical and qualitative vs. quantitative approaches. This in turn has yielded a set of significant advancements in theory building, measurement methods, or risk management models, while practical and quantitative knowledge regarding the phenomena that are at the root of supply chain interruptions has lagged behind those advancements. For instance, the studies of Bode and Wagner (2015) and Revilla and Saenz (2017), just to cite two noteworthy examples, have claimed that to date studies on supply chain risk management have been more theoretical and qualitative than empirical and quantitative, so we are failing to know the precise extension of this phenomenon in practice, mainly because one important element of risk that remains largely unexplored is the frequency (or likelihood) of supply chain disruptions, since most studies have investigated the firm's losses if a disruption actually occurs (Hendricks et al., 2009) but have failed to illustrate how often this happens and why it occurs. 
sinergie Vol. 39, Issue 3, 202

This study gives answer precisely to these two questions: how often is one supply chain continuity broken? And what are the reasons that make this happen? It does so through a large range empirical data collection that took place in 2019 and involved 147 Italian manufacturing firms. As it happens in any other empirical study, the sample of firms considered by this research is limited both in time and space. The time limitation could lead to biased results because certain periods of time are intrinsically more (or less) perturbated than others. We investigated supply disruptions spanning from 2010 to 2019, so the global financial crisis epitomized by the famous Lehman Brothers default in September 2008 could have had an impact on the default rate of companies in the first years of the considered time period, while if we will repeat this study in years to come, we could uncover a new very perturbated period in connection with the COVID-19 pandemic. The space limitation implies the investigation of a rather limited number of firms, which refer to a certain geographical territory and industrial sector (in our case manufacturing firms that operate in Italy). So, our results might be fully valid only for the considered time period, geographical extension and branch of industry. Moreover, dealing with a limited number of responding firms which therefore imply a rather limited number of defaults, any empirical investigation can encounter difficulties in overcoming the background noise produced by the intrinsically uncertain and uncontrollable way the data are gathered and collected.

However, while this study undoubtedly has, to some extent, these limitations, it still presents a rather robust and straightforward quantitative analysis of the supply interruption phenomenon and of its cause(s) and provides valid answers to the two basic questions that were left unresolved in the views of the aforementioned researchers. Firms that answered to our questionnaire were found to suffer, on average, slightly less than 2 supply interruptions per year and every 100 suppliers, almost half of them due to suppliers' financial default. While the numerical values could be considered endogenous characteristics of the peculiar businesses and time period studied, the main messages that these numbers bring to our attention has a more general validity: i). the unforeseen and sudden interruption of supply chains is a very relevant phenomenon that deserves to be analyzed by researchers and considered by managers in its own right; ii). while supply chain continuity interruptions happen because of a very large range of differentiated reasons, by and large the most important of them is the financial default of suppliers.

\subsection{Managerial implications}

In addition to the gap in academic research that this paper contributes to fix, and in close connection with the answers that it gives to the research questions investigated, this paper further supports some considerations that could help managers to ensure their supply chain's continuity.

First of all, the evidence here discussed about supply chain interruptions frequency of occurrence forces companies towards investing in professional managers, organizational procedures and software tools that enable the setting-up of an effective supply chain risk management 
preventive system as suggested by El Baz and Ruel (2021), dealing with all the 4 phases proposed: risk identification, risk assessment, risk mitigation and risk control. So, one further topic that the prosecution of this study will deal with is to better investigate what is the attitude of firms towards supply chain risk management, what are they doing in order to prevent and react to interruptions, and which results are they achieving out of these actions.

The evidence that large firms are on average much better than smaller ones in filtering out, preventing and controlling this phenomenon can probably be explained by the fact that supply risk management as a whole is a rather new discipline that requires a very deep and specific knowledge, and therefore large businesses are more likely to be equipped with skilled managers, adequate managerial and organizational procedures and appropriate software applications dedicated to deal with it than their smaller counterparts. We hope to be able to investigate this evidence more in deep in the next phases of this research program. However, while this improved ability seems to do miracles in reducing overall supply chain interruptions by almost three quarters, it proves much less effective when we measure out its ability to reduce those interruptions due to suppliers' financial default, which means that large firms are super-good as compared to micro-ones at reducing all the other numberless causes that can provoke a supply interruption. This, in turn seems to strongly suggest that either even large businesses are not doing enough to cope with this most important of the supply chain interruption causes, or this very cause is the main one just because it is so elusive and difficult to forecast, or both. Indeed, any of these considerations seems quite surprising, in the light of the fact that financial credit scoring is a well-developed industry, and commercial services that crunch corporate financial statements data in order to analyze and forecast firms' financial stability are a widely used commodity. Thus, we believe that to understand more in deep how this apparent paradox can be explained is a major objective of our further analyses.

Another interesting empirical evidence brought to light by this paper is the clear connection between supply chain complexity and its vulnerability to supply chain continuity issues. In fact, responding firms that belong to industry sectors with more complex supply chains (notably: capital and durable goods) experience overall less supply chain interruptions than their counterparts in simpler supply chains, but a much larger impact of suppliers' financial default. On the one side, this is fully in line with previous supply chain risk management literature, for instance Hallikas et al. (2002 and 2004) and Harland et al. (2003)) and also with supply chain complexity literature (for instance Perona and Miragliotta (2004). On the other hand, it offers an interesting information to better direction the efforts especially of managers within these sectors. Looking at the specific characteristics of these two sectors, there are several reasons why supply complexity can make a supply chain more vulnerable to interruptions. The first and most obvious is that when you have to manage a larger supplier base it is more difficult to keep all your suppliers under control. In addition to that, especially in capital goods, products tend to be less standard, and therefore also the supplier base can be less static, another factor that can add uncertainty. Finally, capital goods are typically produced in rather small 
Sinergie

Vol. 39, Issue 3, 202

quantities, so volumes purchased can be also rather small, which in turn could prevent firms from recurring to large and well-established suppliers, and instead to address smaller and more "volatile" business partners.

\section{Conclusions}

Although the full potential of this study will only be achieved through a more complete and straightforward elaboration of empirical results, that will leverage on the whole set of empirical data achieved, the discussion of partial empirical results that is performed in this paper can take us to some relevant and distinctive concluding remarks. This paper fills a gap in the extant literature by supplying quantitative and empirical data regarding the frequency of supply interruptions and their causation. Moreover, in doing so it presents managers with some critical considerations about their current curse of action regarding supply chain risk management, and how it could become more efficient and effective.

A second valuable contribution of this study is that it is the first to analyze the vast dataset collected through a large- scale empirical survey. As such, it opens-up to many further questions that will hopefully find an answer. For instance, it could be more profoundly investigated if and how supply interruptions suffered by companies depend on such endogenous factors of the investigated firms' supply chains, as the procurement and supply policies applied, managers' experience and competence, or their awareness of the problem. In connection to this, it could as well be studied if and how supply interruptions are connected also to how procurement and suppliers are managed, a thesis that is supported, among others, by Caniëls and Geldermann (2007). On top of that, the data collected by means of this research program can also support a study of how do investigated companies provide to the analysis, definition and measure of supply risk, to which an extent they actually care about it, and which are the effects of supply relations disruptions, in terms of time required to get back to a new steady state and cost implied by it.

\section{References}

AHMED A., KAYIS B., AMORNSAWADWATANA S. (2007), "A review of techniques for risk management in projects", Benchmarking: an International Journal, vol. 14, n. 1, pp. 22-36.

AVENN T. (1992), Risk Analysis and Management. Basic Concepts and Principles, University of Stavanger, Norway.

BLOS M.F., HOEFLICH S.L., MIYAGI P.E. (2015), "A general Supply Chain Continuity Management Framework", Procedia of Computer Science, vol. 55, pp. 1160-1164.

BODE C., WAGNER S.M. (2015), "Structural drivers of upstream supply chain complexity and the frequency of supply chain disruptions", Journal of Operations Management, vol. 36, pp. 215-228. 
CANIËLS M.C.J., GELDERMANN C.J. (2007), "Power and interdependence in buyer supplier relationships: A purchasing portfolio approach", Industrial Marketing Management, vol. 36, n. 2, pp. 219-229.

CIGOLINI R., COZZI M., PERONA M. (2004), "A new framework for supply chain management", International Journal of Operations and Production Management, vol. 24, n. 1, pp. 7-41.

COLICCHIA C., DALLARI F., MELACINI M. (2011), "A simulation-based framework to evaluate strategies for managing global inbound supply risk", International Journal of Logistics Research and Applications, vol. 14, n. 6, pp. 371-384.

COOPER M.C., ELLRAM L.M. (1993), "Characteristics of Supply Chain Management and the Implications far Purchasing and Logistics Strategy", The International Journal of Logistics Management, vol. 4, n. 2.

EL BAZ J., RUEL S. (2021), "Can supply chain risk management practices mitigate the disruption impacts on supply chains' resilience and robustness? Evidence from an empirical survey in a COVID-19 outbreak era", International Journal of Production Economics, vol. 233, in the press

HALLIKAS J., LINTUKANGAS K. (2016), "Purchasing and supply: An investigation of risk: management performance", International Journal of Production Economics, vol. 17 , Part 4, pp. 487-494.

HALLIKAS J., VIROLAINEN V.M., TUOMINEN M. (2002), "Risk analysis and assessment in network environments: A dyadic case study", International Journal of Production Economics, vol. 78, n. 1, pp. 45-55.

HALLIKAS J., KARVONEN I., PULKKINEN U., VIROLAINEN V.M., TUOMINEN M. (2004), "Risk management processes in supplier networks", International Journal of Production Economics, vol. 90, n. 1, pp. 47-58.

HARLAND C., BRENCHLEY R., WALKER H. (2003), "Risk in supply networks", Journal of Purchasing and Supply Management, vol. 9, n. 2, pp. 51-62.

HECKMAN I., GOMES T., NICKEL S. (2015), "A critical review on supply chain risk - Definition, measure and modeling", OMEGA, vol. 52, April, pp. 119132.

HENDRICKS K.B., SINGHAL V.R., ZHANG R. (2009), “The effect of operational slack, diversification, and vertical relatedness on the stock market reaction to supply chain disruptions", Journal of Operations Management, vol. 27, n. 3, pp. 233-246.

HOFFMANN P., SCHIELE H., KRABBENDAM K, (2013), "Uncertainty, supply risk management and their impact on performance", Journal of Purchasing and Supply Management, vol. 19, n. 3, pp. 199-211.

HULT J.T.M., CRAIGHEAD C.W., KETCHEN D.J. (2010), "Risk Uncertainty and Supply Chain Decisions: A Real Options Perspective”, Decision Sciences, vol. 41, n. 3, pp. 435-458.

JÜTTNER U. (2005), "Supply chain risk management. Understanding the business requirements from a practitioner perspective", The International Journal of Logistics Management, vol. 16, n. 1, pp. 120-141.

KANEMANN D., TVERSKY A. (1979), "Prospect Theory: an analysis of decision under risk", Econometrica vol. 47, n. 2, pp. 263-291.

KROLAS P., KROLAS L. (2010), "Risk in Management Systems according to ISO Standard", Archives of Foundry Engineering, vol. 10 Special Issue 3/2010, pp. 149-152.
Marco Perona

Supply Risk Management

empirical perspective on

he Italian manufacturing

sector 
MICHELI G.J.L. (2008), “A decision-maker-centred supplier selection approach for critical supplies", Management Decision, vol. 46, n. 6, pp. 918-932.

MICHELI G.J.L., CAGNO E., ZORZINI M. (2008) "Supply risk management vs supplier selection to manage the supply risk in the EPC supply chain", Management Research News, vol. 31, n. 11, pp. 846-866.

MICHELI G.J.L., CAGNO E., DI GIULIO A. (2009), "Reducing the total cost of supply through risk-efficiency-based supplier selection in the EPC industry", Journal of Purchasing and Supply Management, vol. 15, n. 3, pp. 166-177.

MISHRA D., SHARMA R.R.K., KUMAR S., DUBEY R. (2016), "Bridging and buffering: Strategies for mitigating supply risk and improving supply chain performance", International Journal of Production Economics, vol. 180, October, pp. 183-197.

MORGENSTERN O., VON NEUMANN J. (1944), Theory of games and economic behavior, Princeton University Press.

OJALA M., HALLIKAS J. (2006), "Investment decision-making in supplier networks: Management of risk", International Journal of Production Economics, vol. 104, n. 1, pp. 201-213.

PERONA M., MIRAGLIOTTA G. (2004), "Complexity Management and Supply Chain performance assessment. A field study and a conceptual framework", International Journal of Production Economics, vol. 90, n. 1, pp. 103-115.

PETTIT T.J., CROXTON K.L., FIKSEL J. (2013) "Ensuring Supply Chain Resilience: Development and Implementation of an Assessment Tool", Journal of Business Logistics, vol. 34, n. 1, pp. 46-76.

PRANDI P. (2010), Il Risk Management. Teoria e pratica nel rispetto della normativa, Franco Angeli, Milano.

REVILLA E., SAENZ M.J. (2017), "The impact of risk management on the frequency of supply chain disruptions: a configurational approach", International Journal of Operations and Producion Management, vol. 37, n. 5, pp. 557-576.

SODHI M.S., SON B.G., TANG C.S. (2012), "Researchers' Perspectives on Supply Chain Risk Management”, Production and Operations Management, vol. 21, n. 1, pp. 1-13.

TANG O., NURMAYA MUSA S. (2011), "Identifying risk issues and research advancements in supply chain risk management", International Journal of Production Economics, vol. 133, n. 1, pp. 25-34.

THUN J.E., HÖNIG D. (2011), "An empirical analysis of supply chain risk management in the German automotive industry", International Journal of Production Economics, vol. 131, n. 1, pp. 242-249.

WAGNER S.M., BODE C. (2006), "An empirical investigation into supply chain vulnerability", Journal of Purchasing and Supply Management, vol. 12, n. 6, pp. 301-312.

WANG Y., WENDELL G., TOMLIN B. (2010), "Mitigating Supply Risk: Dual Sourcing or Process Improvement?", Manufacturing and Service Operations Management, vol. 12, n. 3, pp. 371-545.

WIELAND A., WALLENBURG C.M. (2012) "Dealing with supply chain risks. Linking risk management practices and strategies to performance", International Journal of Physical Distribution and Logistics Management, vol. 42, n. 10, pp. 887-905. 
WIENGARTEN F., HUMPHREYS P., GIMENEZA C., MCIVOR R. (2016), "Risk, Marco Perona risk management practices, and the success of supply chain integration", Supply Risk Management: the Italian manufacturing International Journal of Production Economics, vol. 171, part 3, pp. 361-370. sector

ZSIDISIN G.A., PANELLI A., UPTON R. (2000) "Purchasing organization involvement in risk assessments, contingency plans, and risk management: an exploratory study", Supply Chain Management: An International Journal, vol. 5, n. 4, pp.187-198.

ZSIDISIN G.A. (2003), “Managerial perceptions of supply risk”, Journal of Supply Chain Management, vol. 39, n. 1, pp. 14- 25.

\section{Academic or professional position and contacts}

\section{Marco Perona}

Full Professor of Industrial and Mechanical Engineering

University of Brescia - Italy

e-mail: marco.perona@unibs.it 